\title{
EMERGING TECHNOLOGIES IN THE SERVICE SECTOR: An Early Exploration of Item-Level RFID on the Fashion Sales Floor
}

\author{
Claudia Loebbecke \\ Claudio Huyskens \\ Department of Media and Technology Management \\ University of Cologne \\ Cologne, Germany \\ Janis Gogan \\ Department of Information and Process Management \\ Bentley College \\ Waltham, MA U.S.A.
}

\begin{abstract}
This paper describes the early weeks of a live pilot of item-level RFID by METRO Group's German department store, Kaufhof. The RFID-Enabled Sales Floor utilizes UHF Gen 2 RFID tags on fashion items, combined with RFIDenabled dressing rooms, intelligent displays, and smart mirrors. The pilot represents a pioneering attempt to conduct end-to-end UHF item-level tracking of items through the point-of-sale. Based on an exploratory case study, we reflect on the implications of ubiquitous item-level RFID technology and offer suggestions for further research on the socio-technical implications of this important product and process innovation.
\end{abstract}

Keywords RFID, item level, supply chain, case study, pilot, retailing

We are moving RFID out of the innovation labs, beyond the supply chain, and into working retail stores.

Dr. Gerd Wolfram

Managing Director, METRO Group Information Technology, 2007

Please use the following format when citing this chapter:

Loebbecke, C., Huyskens, C., and Gogan, J., 2008, in IFIP International Federation for Information Processing, Volume 267, Information Technology in the Service Economy: Challenges and Possibilities for the $21^{\text {st }}$ Century, eds. Barrett, M., Davidson, E., Middleton, C., and DeGross, J. (Boston: Springer), pp. 189-198. 


\section{INTRODUCTION}

In recent years many companies have launched pilots to investigate uses of radio frequency identification (RFID) for improved operational control and managerial decision-making (Curtin et al. 2007). In the service sector in general, and more specifically in retailing, a number of companies have demonstrated the value of applying RFID tags to palettes, cases, or cartons to track goods across the supply chain (e.g., Angeles 2005; Loebbecke and Huyskens 2006; Sellitto et al. 2007). However, use of item-level RFID is in a nascent stage; thus far, only small-scale tests have been conducted, in lab-like settings by companies such as Prada (Raafat et al. 2007), Kaufhof and Gerry Weber (Loebbecke and Palmer 2006), Falabella (O'Connor 2007), Mi-Tu (Swedberg 2007a), and Throttleman (Swedberg 2007b). These early RFID trials revealed a variety of challenges, including network problems, poor integration, and lack of standardization with existing enterprise networks (Loebbecke 2006).

To capitalize on new standards set by EPCglobal and ISO, in September 2007, METRO Group and its sales branch Kaufhof, both pioneers in the use of emerging technologies in retailing (e.g., Loebbecke 2004, 2007), moved item-level technology from the lab to real-life on one entire floor in Kaufhof's department store in Essen, Germany (e.g., Wessel 2007). Kaufhof's RFID-Enabled Sales Floor is touted as the first real-life pilot of an end-to-end ultra-high frequency (UHF) generation 2 (Gen2) RFID application using all relevant EPCglobal standards. The purpose of the pilot is to evaluate the use of an emerging, commercially available, and standardized RFID technology on fashion items from their arrival at the store to check-out by shoppers. The system traces the flow of goods throughout the store and uses RFID-enabled smart dressing rooms, smart displays, and a smart mirror to improve the shopping experience.

With this paper, we answer calls for research on emerging information technologies (Curtin et al. 2007; Kendall 1997) with an exploratory study of the first weeks of the Kaufhof pilot. This paper describes the pilot preparations including the RFID item-level infrastructure and applications. Since the pilot is scheduled to run through 2008, it is premature to report on detailed outcomes. Instead, we will initiate an investigation of UHF item-level RFID. This will focus on the issues surrounding RFID as a product or process innovation in the light of ubiquitous computing and its socio-technical implications.

\section{METHOD}

An emerging technology such as item-level RFID cannot be separated from its context of use (Orlikowski 1992). In order to uncover contextual issues, we opted for an exploratory case study (Yin 2003) of a real-world item-level RFID pilot at Kaufhof. Data were gathered by means of public sources and in-depth interviews between December 2006 and November 2007, with managers from METRO Group, Kaufhof, and RFID technology provider Reva Systems. Interviews explored technical and organizational issues in the pilot preparations and the first few weeks of operation, with a focus on the interplay of technical aspects of item-level RFID and the sales floor social system (Scarborough 1995). 


\section{KAUFHOF'S RFID-ENABLED SALES FLOOR}

\subsection{Overview}

In fall 2007, after 10 months of preparation, international retailer METRO Group and its department store chain Kaufhof, together with technology partners Checkpoint Systems, Impinj, and Reva Systems, moved item-level RFID for the second time from a laboratory environment to real-life when they launched the RFID-Enabled Sales Floor in the men's fashion department of a store in Essen, Germany. ${ }^{1}$ Said Ashley Stephenson, Chairman and Co-Founder, Reva Systems, "The RFID network infrastructure controls the whole store experience. For a while, people have been tracking items from the shipper to the distribution center. This is the first time that the spotlight is on the retail sales floor."

In the pilot, all items are individually tagged with UHF Gen2 RFID and tracked from arrival at the store to check-out by shoppers. Sixty readers are installed in twenty locations. METRO Group and Kaufhof expect to "fill the data void that exists from the time that items are received at the store location until they are sold" (Dr. Gerd Wolfram, METRO Group Information Technology, 2007). Specifically, management aims to find answers to questions such as

- How long does it take until items arrive in the store?

- How long do items stay in the store before turnover?

- How does in-store shopping behavior relate to sales?

- What are the implications for store layout and item displays?

\subsection{Pilot Participants}

With 2006 sales of about $€ 60$ billion, METRO Group is the world's third largest retailing company. Its 270,000 employees operate in 2,400 outlets in 30 countries (www.metrogroup.de). Kaufhof Department Stores (Kaufhof), a sales division of METRO Group, operates 146 stores in Germany and Belgium. In 2006, it reported $€ 3.6$ billion sales, of which roughly half resulted from fashion (www.metrogroup.com). In 2003, Kaufhof became an RFID pioneer in the fashion industry when it initiated the Kaufhof-Gerry Weber RFID pilot, testing RFID at unit- and item-level using the high frequency spectrum across the fashion supply chain and in the store before wide-spread RFID standardization. Kaufhof learned that RFID was technically feasible and offered a positive business case as it enabled faster and more precise inventory management, enhanced supply chain processes, and improved customer service (Loebbecke and Palmer 2006). Kaufhof subsequently initiated full RFID roll-out on logistic units such as pallets and boxes in late 2004 (Loebbecke and Huyskens 2006) and envisioned the potential of RFID on item-level.

${ }^{1}$ The pilot is partially conducted under the European Commission funded BRIDGE project (www.bridge-project.eu). 


\subsection{Pilot Preparations}

For the pilot, Kaufhof designed and prepared an entire floor holding men's fashion.

Readers and Antennas. Sixty RFID readers, each with a unique identification, and more than 100 antennas, were installed in the store, along with readers in the back room apparel and shoe storage areas, at the door connecting the back room and sales floor, in service elevators, and at doors covering goods shipments and receipts. On the sales floor, reader locations include dressing rooms, areas where shoppers try on shoes, the "return to floor" rack, shelves and racks for shoes, accessories and apparel, floor displays, promotion displays, checkout counter, checkout line, and exits (main door, customer elevators, and escalators). Together the reading zones cover about 30,000 individual fashion goods. All antennas are tuned for near-field operation in a clearly defined reading zone (hoping to avoid the "unwanted reads" problem). An early technical challenge was tuning antennas for this dense reader environment, in which each tag would be read by more than one reader. Display furniture and portions of checkout counters were shipped to technology vendor Impinj in Seattle, where engineers customized readers and antennas to achieve a read-rate better than the 95 percent METRO Group requirement.

Smart Displays. In the Gardeur shop-in-shop, ${ }^{2}$ Kaufhof installed five smart shelves and tables, four smart dressing rooms, and a smart mirror. RFID-enabled smart shelves and tables help consumers quickly find the proper sizes. When shoppers approach a shelf or table containing dozens of folded shirts, they can find out if a shirt with their neck size and arm length is available without digging through all of the shirts. A reader on the display interrogates the shirts' RFID tags and updates a list of sizes for shoppers.

A reader in the smart dressing room recognizes the exact item a shopper brings in, and a touch screen displays additional product information, such as material, price, care instructions, and other available sizes and colors. In the future, smart dressing room software will offer suggestions regarding apparel coordination by, for instance, displaying a written description, photograph and/or video of an appropriate shirt or tie, ideally one that is available in the store.

The smart mirror outside the dressing room provides similar information. At shoppers' requests, the mirror will display the item in a different size or color and note its location (on the floor, in the stock room, or on order). Future plans call for software that will display descriptions, photographs, or videos of appropriate accessories that can be purchased.

In order for the RFID-enabled sales floor to be fully functional, all 60 readers in the store need to be connected to Kaufhof's enterprise applications. Tag acquisition processors (TAPs) and a standardized tag acquisition network (TAN) are provided by Reva Systems to connect the reader layer to Kaufhof's enterprise network. The TAPs centrally manage multi-vendor RFID readers as network elements. They combine real-time adaptive reader control, location-aware tag data processing, and standard-based data services, enabling them to deliver accurate, actionable RFID data to the application layer. The TAN manages readers in real-time as parts of an overall enterprise network architecture, relates data to a specific source and its location, and provides applications and back-

${ }^{2}$ Manufacturers design and staff specifically branded "shops-in-shops" within Kaufhof stores. 
office systems with standardized data services. A key feature of the TAN is that it conducts singulation, which helps avoid problems when tags are covered by multiple readers (Krishna and Husak 2007).

Other Sales Floor Preparation. At Kaufhof's regional distribution center, UHF Gen2 RFID tags are attached to each item to be sold in the pilot department store. ${ }^{3}$ With RFID readers on conveyors and packing-tables, Kaufhof scans the RFID tags as items are packed or moved. It relies on UHF dock-door portals to read the tags when items are shipped from the distribution center to the pilot department store.

As items arrive at the store, RFID portals in the back room are utilized for confirming their receipt. On the sales floor, employees hang clothes on racks and assign RFID tags on items to the RFID reader of the rack. Inventory software can then check whether items are located in their assigned racks.

To reassure shoppers regarding perceived privacy intrusion, signs and flyers posted throughout the store explain the RFID technology and its applications. At the cash register, employees inform shoppers that RFID tags can be discarded or retained for use as an electronic receipt for potentially returning an item.

\subsection{In-Store Processes}

Kaufhof can capture real-time data on various employee- and shopper-based activities.

RFID data - gathered when employees unload goods, store items in the back room, or move them to other floors - reveal which items are in the sales room and which ones need to be put on display. Inventory data inform employees of items to be taken off sales floor shelves (e.g., as seasons change). Dressing room data identify items that shoppers leave behind and direct employees to return them to the sales floor. Data provided via handheld readers help employees find specific items for customers.

RFID data help identify which items shoppers pick, purchase, or reject. Readers at escalators and in elevators show when shoppers move one or more items across floors. Readers on shelves identify when shoppers pick an item and whether shoppers take it to a dressing room or proceed directly to the checkout line. As shoppers approach checkout, an RFID reader installed under the counter reads each item's tag to update the sales system. If an item is placed on the counter but not purchased, Kaufhof requires an employee to read the tag using a handheld reader and thus informs the system.

\subsection{Use Cases: Data Analysis Possibilities}

Data captured at each reading instance of a tag as outlined above could be fed into a central data repository. Filling this data void is only the first step. Subsequently, Kaufhof will determine which of the data analysis possibilities and respective queries to the data repository given below will be technically sustainable and economically meaningful.

${ }^{3}$ In addition, Kaufhof outfits each item with a usual hangtag showing the price and bar-coded stock-keeping unit (SKU) number. 
Concerning store deliveries and returns, Kaufhof could query which items have actually arrived on the store premises and which items have been checked into the store "returns" location. Subsequent analysis could reveal how long it takes before returns are picked up again and when they are shipped back to the distribution center. Weekly or even daily inventory counts could become possible. The system could report on daily, weekly, seasonal, or yearly turnover of individual items and could easily and quickly identify the fastest sell-through items and slow sellers, as well as those newly delivered items which are sold ahead of existing stock.

Kaufhof could also analyze whether an item was tried on prior to purchase and whether a purchased item was the first one a shopper picked and carried through the store (which might indicate that he entered the store intending to purchase that particular item). The system could reveal how much time shoppers spend in the check-out line before actually making a purchase, and whether an item sold was selected from a promotional display.

Further, the system could reveal which items shoppers try on and how many they buy, how long shoppers wait for a dressing room, what percentage of items are brought into dressing rooms, and how long rejected items stay off the sales floor. From such queries, Kaufhof could determine the actual locations for particular items. Kaufhof could derive insights about promising item positioning (shelves, racks, promotional displays) and location (near escalators or dressing rooms) and whether shoppers' behavior changes as a result of promotions, store layout, or employee actions. Also, Kaufhof could analyze how much time shoppers spend in line at checkout.

In terms of stocking decisions, Kaufhof could investigate how long items stay in the back room before moving to the sales floor, how many items are returned from the sales floor to the back room, and which items shoppers return to the store. With regard to theft prevention, the system may shed light on when and where missing items were last seen. Kaufhof could match clips of a security video, indexed via location and time, with RFID data.

\section{CONCEPTUAL TRAJECTORIES}

Occasionally, a new technology like UHF Gen 2 item-level RFID emerges with the potential to enhance an organization's ability to capture, analyze, store, distribute and retain valuable information for improved operations and analysis.

Early-stage pilots such as Kaufhof's RFID-Enabled Sales Floor offer clues as to how organizations could utilize RFID on the fashion floor. Organizations can gain reliable and useful data to inform management's decision-making. For instance, RFID-enabled traceability of items throughout the store may lead to more complete assortments, shorter waiting times, and enhanced customer experience, including the ability to find items that shoppers seek faster (e.g., Hardgrave et al. 2007). The marriage of item traceability with smart displays may facilitate interactions with shoppers and thus enable innovative services, competitive differentiation and improved profits. However, for these benefits to be achieved there are numerous challenges, which can be examined in future studies through several theoretical lenses. 
Item-level RFID as product or process innovation. Research on product and process innovations (e.g., Benamati and Lederer 2001; Day and Schoemaker 2000; Jarvenpaa and Ives 1996; Van de Ven 2005) provides relevant insights for studying item-level RFID as an emerging technology. As a product innovation, there is potential for itemlevel RFID to rewrite the rules of competition and potentially alter entire industries (Gebauer and Segev 2000). However in IS research, emerging infrastructure technologies have been distinguished from product innovations (Robey 1986) and considered as process innovations (Zmud 1982). As a process innovation, item-level RFID could enable (or conversely, constrain) new models for managing and utilizing finer-grained data.

Item-level RFID raising ubiquitous computing to a new level. As this emerging technology moves to multi-application, enterprise-wide deployments, RFID readers could become the most numerous and densely deployed network devices, with both positive and negative ramifications. Item-level traceability can reveal new information about shoppers' interests and behaviors and increase organizations' monitoring capabilities (Price et al. 2005), extending the literature on ubiquitous computing and networked organizations. At the same time, ubiquitous RFID gives rise to privacy concerns (Shapiro and Baker 2001; Spiekermann and Ziekow 2006) and suggests investigating the counterintuitive, adverse behavioral effects (Scheepers et al. 2006) more fully.

Socio-technical impacts of item-level RFID. As computing devices become ubiquitous, they give rise to new categories of applications and new relationships among users and between users and technologies. As item-level RFID becomes ubiquitous, new context-aware and/or location-based services will be developed. As managers, employees, and customers gain experience with these applications, there will be significant ramifications for organizations and industries (Lyytinen and Yoo 2001; Weiser 1999). To understand the ramifications of ubiquitous item-level RFID it is helpful to explore the socio-technical processes that lead to acceptance and seamless use in some contexts and not in others (Lyytinen and Yoo 2002). The mutual accommodation of technical features of item-level RFID and human processes requires further study, since prior research (DeSanctis and Poole 1994; Orlikowski 1992) finds that technology behaves as an influential agent in the organizational context. Thus, future studies may investigate how specific characteristics of item-level RFID constrain or enable users and explore new structures which emerge from its use. For example, it would be helpful to closely examine how shopper and employee behavior and attitudes influence the organizational change initiated by the implementation of item-level RFID technology. It would be of similar interest to investigate how the ubiquity of item-level RFID leads to challenges associated with customers' privacy and trust (Shapiro and Baker 2001; Weiser 1991). Finally, as item-level RFID also increases the amount of data available to managers, research may want to explore the resulting implications for companies' monitoring capabilities and control over assets (Curtin et al. 2007).

\section{References}

Angeles, R. 2005. "RFID Technologies: Supply-Chain Applications and Implementation Issues," Information Systems Management (22:1), pp. 51-65.

Benamati, J., and Lederer, A. 2001. "Rapid Information Technology Change, Coping Mechanisms, and the Emerging Technologies Group," Journal of Management Information Systems (17:4), pp. 183-202. 
Curtin, J., Kauffmann, R., and Riggins, F. 2007. "Making the 'Most' out of RFID Technology: A Research Agenda for the Study of the Adoption, Usage and Impact of RFID," Information Technology Management (8:2), pp. 87-110.

Day, G., and Schoemaker, P. 2000. "Avoiding Pitfalls of Emerging Technologies," California Management Review (42:2), pp. 8-33.

DeSanctis, G., and Poole, M. 1994. "Capturing the Complexity in Advanced Technology Use: Adaptive Structuration Theory," Organization Science (5:2), pp. 121-147.

Gebauer, J., and Segev, A. 2000. "Emerging Technologies to Support Indirect Procurement: Two Case Studies from the Petroleum Industry," Information Technology and Management (1:1/2), pp. 107-128.

Hardgrave, B., Armstrong, C., Riemenschneider, C. 2007. "RFID Assimilation Hierarchy," in Proceedings of the $40^{\text {th }}$ Annual Hawaii International Conference on System Sciences, Waikoloa, Big Island, HI, January 3-6, p. 224b..

Jarvenpaa, S., and Ives, B. 1996. "Introducing Transformational Information Technologies: The Case of the World Wide Web Technology," International Journal of Electronic Commerce (1:1), pp. 95-126.

Kendall, K. 1997. "The Significance of Information Systems Research on Emerging Technologies: Seven Information Technologies that Promise to Improve Managerial Effectiveness," Decision Sciences (28:4), pp. 775-792.

Krishna, P., and Husak, D. 2007. "RFID Infrastructure," Communications Magazine, IEEE (45:9), pp. 4-10.

Loebbecke, C. 2004. "Modernizing Retailing Worldwide at the Point of Sale," MIS Quarterly Executive (3:4), pp. 177-187

Loebbecke, C. 2006. "RFID in the Retail Supply Chain," in Encyclopedia of E-Commerce, EGovernment and Mobile Commerce, M. Khosrow-Pour (ed.), Hershey, PA: Idea Group Publishing, pp. 948-953.

Loebbecke, C. 2007. "Piloting RFID Along the Supply Chain: A Case Analysis," Electronic Markets (17:1), pp. 29-37.

Loebbecke, C., and Huyskens, C. 2006. "Weaving the RFID Yarn in the Fashion Industry: The Kaufhof Case," MIS Quarterly Executive (5:4), pp. 169-179.

Loebbecke, C., and Palmer, J. 2006. "RFID in the Fashion Industry: Kaufhof Department Stores AG and Gerry Weber International AG, Fashion Manufacturer," MIS Quarterly Executive (5:2), pp. 15-25.

Lyytinen, K., and Yoo, Y. 2001. "The Next Wave of Nomadic Computing: A Research Agenda for Information Systems Research," Sprouts: Working Papers on Information Environments, Systems and Organizations (1:1), pp. 1-12.

Lyytinen, K., and Yoo, Y. 2002. "Issues and Challenges in Ubiquitous Computing," Communications of the ACM (45:12), pp. 63-65.

O'Connor, M. 2007. "Falabella Plans Second Item-Level RFID Pilot," RFID Journal, August 29 (www.rfidjournal.com/article/articleview/3585/1/1/definitions_on).

Orlikowski, W. 1992. "The Duality of Technology: Rethinking the Concept of Technology in Organizations," Organization Science (3:3), pp. 398-427.

Price, B., Adam, K., and Nuseibeh, B. 2005. "Keeping Ubiquitous Computing to Your-Self: A Practical Model for User Control of Privacy," International Journal of Human-Computer Studies (63:1/2), pp. 228-253.

Raafat, F., Sherrard, W., Meslis, L., and Windt, J. 2007. "Case Study: Applications of RFID in Retail Business," in Proceedings of the 2007 Meeting of the South West Region of the Decision Sciences Institute, San Diego, CA, pp. 695-701.

Robey, D. 1986. Designing Organizations ( $2^{\text {nd }}$ ed.), Homewood, IL: Irwin.

Scarbrough, H. 1995. "Review Article on The Social Engagement of Social Science," Human Relations (48:1), pp. 1-11. 
Scheepers, R., Scheepers, H., Ngwenyama, O. 2006. "Contextual Influences on User Satisfaction with Mobile Computing: Findings From Two Healthcare Organizations," European Journal of Information Systems (15:3), pp. 261-268.

Sellitto, C., Burgess, S., and Hawking, P. 2007. "Information Quality Attributes Associated with RFID-Derived Benefits in the Retail Supply Chain," International Journal of Retail \& Distribution Management (35:1), pp. 69-87.

Shapiro, B., and Baker, C. 2001. "Information Technology and the Social Construction of Information Privacy," Journal of Accounting and Public Policy (20:4/5), pp. 295-322.

Spiekermann, S., and Ziekow, H. 2006. "RFID: A Systematic Analysis of Privacy Threats and a 7-Point Plan to Adress Them," Journal of Information System Security (1:3), pp. 2-17.

Swedberg, C. 2007a. "Hong Kong Shoppers Use RFID-Enabled Mirror to see what they Want," RFID Journal, September 4 (www.rfidjournal.com/article/articleview/3595/).

Swedberg, C. 2007b. "Throttleman Adopts Item-Level Tagging," RFID Journal, August 24 (www.rfidjournal.com/article/articleview/3580/).

Van de Ven, A. 2005. "Running in Packs to Develop Knowledge-Intensive Technologies," MIS Quarterly (29:2), pp. 365-378.

Weiser, M. 1991. "The Computer of the 21st Century," Scientific American (265:3), pp. 66-75.

Weiser, M. 1999. "Some Computer Science Issues in Ubiquitous Computing," Mobile Computing and Communication Review (3:3), pp. 12-21.

Wessel, R. 2007. "Metro Group's Galeria Kaufhof Launches UHF-Item-Level Pilot," RFID Journal, September 20 (www.rfidjournal.com/article/articleview/3624).

Yin, R. 2003. Case Study Research: Design and Methods ( $5^{\text {th }}$ ed.), Thousand Oaks, CA: Sage Publications.

Zmud, R. 1982. "Diffusion of Modern Software Practices: Influence of Centralization and Formalization," Management Science (28:12), pp. 1421-1431.

\section{About the Authors}

Claudia Loebbecke holds the Chair of Media and Technology Management at the University of Cologne, Germany. In 2005-2006, she was elected President of the Association for Information Systems (AIS). She also worked and researched at the London School of Economics, Bentley College, CISR (at Massachusetts Institute of Technology), INSEAD, Copenhagen Business School, Erasmus University, Hong Kong University of Science and Technology, University of New South Wales, and McKinsey \& Co. She is a senior editor for Journal of Strategic Information Systems, an associate editor for The Information Society, and is on the editorial boards of several IS and media journals. Claudia received a Master's and a Ph.D. in Business Administration, both from the University of Cologne, and an MBA from Indiana University, Bloomington, Indiana. She has published over 150 internationally peer-reviewed journal articles and conference papers (see www.mtm.uni-koeln.de/team-loebbecke-home-engl.htm). Claudia can be reached at claudia.loebbecke@uni-koeln.de.

Claudio Huyskens is a Ph.D. candidate in the Department of Business Administration, Media and Technology Management at the University of Cologne, Germany. He holds a Master's degree in Business Administration from the University of Cologne. His research covers RFID technology in supply chains, IT outsourcing via the Internet, and new media entrepreneurship. His publications appear in several journals (e.g., MIS Quarterly Executive, European Journal of Information Systems, Electronic Markets, European Journal of Operational Research) and conference proceedings (see www.mtm.uni-koeln.de/team-huyskens-home-engl.htm). Claudio can be reached at claudio.huyskens@uni-koeln.de.

Janis L. Gogan holds Ed.M., MBA, and DBA degrees from Harvard University. A member of the Information \& Process Management faculty of Bentley College, Janis teaches IT management and strategy courses and has published about 80 refereed papers in conference proceedings 
and journals (such as Communications of the Association for Information Systems, Electronic Markets, International Journal of Electronic Commerce, Journal of Information Systems, Journal of Information Technology, and Journal of Management Information Systems). Her publications also include numerous book chapters, Information Week columns, and teaching cases which have been taught in the U.S., European, Australian, and Asian schools. Her current research examines two topics: the management of emerging information technologies and interorganizational information sharing under time pressure. Janis can be reached at jgogan@bentley.edu 